\title{
EXPERIMENTAÇÕES DRAMATÚRGICAS E HOMOSSEXUALIDADE FEMININA EM PEÇAS EM UM ATO DE TENNESSEE WILLIAMS Why Do You Smoke So Much, Lily? e Something Unspoken
}

\author{
EXPERIMENTACIONES DRAMATÚRGICAS Y HOMOSEXUALIDAD \\ FEMENINA EN PIEZAS EM UN ACTO DE TENNESSEE WILLIAMS \\ Why Do You Smoke So Much, Lily? y Something Unspoken
}

\section{DRAMATURGIC EXPERIMENTS AND FEMALE HOMOSEXUALITY IN TENNESSEE WILLIAMS ON-ACT PLAYS Why Do You Smoke So Much, Lily? and Something Unspoken}

\author{
Luis Marcio Arnaut de Toledo
}

\begin{abstract}
RESUMO
Este trabalho faz uma análise das peças em um ato Why Do You Smoke so Much, Lily? (1935) e Something Unspoken (1958), focalizando o retrato histórico, político e social da mulher em que foram escritas e suas reverberações na contemporaneidade, afastandose da visão hegemônica da obra de Tennessee Williams - psicologizante e autobiográfica. Evidencia-se nestas duas peças um alinhamento entre elas a partir do retrato da mulher homossexual e sua quase total alienação e opressão na sociedade heteronormativa. Além disso, são destacados os recursos experimentais para criar tais representações, desafiando a forma dramática convencional com elementos épico-líricos e o expressionismo.
\end{abstract}

PALAVRAS-CHAVE: Tennessee Williams, Dramaturgia Norte-americana, Homossexualidade Feminina, Teatro Épico, Teatro Expressionista.

\section{RESUMEN}

Este trabajo hace un análisis de las piezas de un acto Why Do You Smoke so Much, Lily? (1935) (1935) y Something Unspoken (1958), enfocando el retrato histórico, político y social de la mujer en que fueron escritas y sus reverberaciones en la contemporaneidad, huyendo de la visión hegemónica del obra de Tennessee Williams psicologizante y autobiográfica. Se evidencia en estas dos piezas un alineamiento entre ellas, a partir del retrato de la mujer homosexual y su casi total alienación y opresión en la sociedad heteronormativa. Además, se destacan los recursos experimentales para crear tales representaciones, desafiando la forma dramática convencional con elementos épico-líricos y el expresionismo.

PALABRAS-CLAVE: Tennessee Williams, Dramaturgia Norteamericana, Homosexualidad Femenina, Teatro épico, Teatro Expresionista.

\footnotetext{
ABSTRACT

This work analyzes the one-act plays Why Do You Smoke So Much, Lily? (1935) and Something Unspoken (1958), focusing on the historical, political and social portrait of the woman in these plays and their reverberations in the contemporaneity, escaping from the hegemonic vision of the Tennessee Williams plays - psychological and
} 
autobiographical. These two plays show an alignment starting from the portrait of the homosexual woman and her almost total alienation and oppression in the heteronormative society. In addition, experimental features are highlighted to create such representations, challenging the conventional dramatic form with epic-lyrical elements and expressionism.

KEYWORDS: Tennessee Williams, American Drama, Female Homosexuality, Epic Theatre, Expressionist Theatre.

Tennessee Williams possui diversos aspectos em suas obras pouco considerados pela crítica tradicional, pelos artistas em geral e pelos seus admiradores no que diz respeito à visão analítica da sociedade. Suas personagens femininas são tidas como caracterização psicanalítica da realidade que figura uma galeria de mulheres infelizes à beira da histeria, loucura ou pulsões sexuais que as levam às consequências limites, conforme comentam Blackwell (1970), Triplett (1988), Mathur (2002), Kataria (2011) e Foley (2013). No entanto, esta leitura não possibilita uma visão completa do conjunto de obras do dramaturgo, deixando de lado questões sociais e históricas e, inclusive, contextos políticos de diversas matérias ficcionais de sua obra, entre eles os das personagens femininas, considerados apenas como superficialidades ou pano de fundo para suas histórias.

Segundo a pesquisadora Maria Silvia Betti (2011, p. 97), as peças em um ato do autor são negligenciadas no campo editorial, pela crítica dita especializada e pelos encenadores e, por isso, quase nunca montadas ou citadas. Nos Estados Unidos, após a década de 1990 este conjunto de obras foi fartamente montado em diversas regiões do país. São peças em que não há desfecho evidente (TORRES, 2012) e a incomunicabilidade leva a situações onde os diálogos são menos claros que a própria situação. O autor lança mão de recursos expressionistas, no caso das peças de Tennessee entre 1930 a 1961 e, nas peças após essas datas, proximidades com elementos da dramaturgia de vanguarda dos Estados Unidos do final da década de 1950 até 1970. Este material, vai além de uma suposta representação realista e aproxima-se de reflexões incomuns na dramaturgia estadunidense até então. Analisálas possibilita dar luz a um conjunto profícuo de sua obra e lançar luz sobre uma 
produção artística que o levou a ser considerado "o mestre da forma dramatúrgica curta" (KEITH, 2016, p. xiv). ${ }^{1}$

Os trabalhos de Williams aqui cotejadas são as peças em um ato: Why Do You Smoke So Much, Lily? e Something Unsponken, cujas traduções são Por Que Você Fuma Tanto, Lily? e Algo Não Dito, a partir dos mesmos dispositivos analíticos utilizados por Arnaut (2017). Desta forma, considera apenas os aspectos sóciohistóricos como determinantes para a caracterização das personagens femininas e a historicização da mulher na sociedade estadunidense, deixando de lado o realismo psicológico e questões autobiográficas, evitando a predisposição hegemônica de suas caracterizações, ainda que pertinente, mas não considerada como componente dramatúrgico mais relevante.

Ao se tornar celebridade, o mercado impôs a Tennessee Williams a necessidade de produzir obras-primas após o sucesso de The Glass Menagerie (1944) [À Margem da Vida, primeira tradução da peça, ou $O$ Zoológico de Vidro, última tradução publicada no Brasil]. As peças em um ato foram uma saída para suprir as demandas de consumo de sua obra, desde que são mais curtas para serem concluídas. As estruturas da linguagem utilizadas por Williams nestes trabalhos deixam, muitas vezes, silêncios mais evidentes que as falas, assim como lacunas e metáforas que se assemelham aos recursos cíclicos do enredo de peças de Beckett. Mas, talvez seja mais uma aproximação do existencialismo, com reflexões sobre o ser e a vida, do que uma expressa vontade de fazer algo como o chamado teatro do absurdo tal como Ionesco ou Pinter (SADDIK, 2015).

Flores (2015, p. 64) pontua que as peças em um ato não são esboços de personagens e rascunhos para futuras peças longas, consideradas canônicas. Há, certamente, como diz o autor, alguns pontos em comum, mas "reduzir a complexidade das personagens e das peças a fim de valorizar os canônicos"2 não seria honesto com esta dramaturgia. "Assim, é mais produtivo - para a crítica, evidentemente - taxá-las de experiências juvenis, não reconhecendo seu valor intrínseco,"3 já que as mais

\footnotetext{
1 "A master of the short form".

2 Id., p. 65.

3 Ibid., p. 67.
} 
famosas são utilizadas na indústria cultural fartamente como produtos assertivos do sucesso.

Há uma galeria de personagens femininas de Tennessee Williams com atenção de críticos e recortes de pesquisadores. Talvez, por este motivo, estas personagens, à primeira vista, tenham um elo com o que se conhece conceitualmente como Southern Belle, as mulheres de origem nobre, descendente da aristocracia francesa colonial. Seu principal objetivo era fazer um casamento arranjado pela família com um cavalheiro sulista antes de completar vinte anos. A pureza era o requisito mais importante para serem consideradas apropriadas aos homens.

Todavia, Tennessee Williams apenas tangenciava o conceito de idealização da mulher na sociedade sulista. Focava na sua decadência, desde que o objeto principal de sua obra sempre foi o retrato de personagens à margem da sociedade, fora do sistema produtivo da sociedade. A composição destas personagens, portanto, contempla a desconstrução da Southern Belle. Strnodová (2013, p. 8) aponta um Tennessee Williams mais crucial com as personagens femininas menos virtuosas e mais conflituosas, ainda que fossem subservientes e oprimidas. Williams trouxe, desta forma, uma visão crítica da mulher na sociedade, fazendo com que o mito contribuísse com a instabilidade e desestruturação da sociedade moderna: Williams elege com ironia o patriarcalismo como promotor da caricatura desta mulher, vítima de ilusões e fantasias impostas (ARNAUT, 2017).

Por outro lado, apresentar personagens gays em sua dramaturgia é "irrepresentável em seu tempo" (BETTI, 2007, op. cit., p. 152). "A palavra homossexual não se materializa verbalmente" em sua obra até suas mais famosas, escritas entre 1944 e 1961, mas reconhecem-se, acima de tudo, "inúmeros signos de uma estética gay", assentindo com Silva (2005, p. 16). O dramaturgo tira o véu da cultura estadunidense sobre a homossexualidade, considerada preconceituosa, repressora, autodestrutiva e homofóbica, exigindo que aqueles que sofrem nestas condições - tal como as mulheres, também oprimidas - sejam ouvidos, representando-os como forasteiros, outsiders, excêntricos, pessoas ameaçadas, oprimidas ou manipuladas pela censura e repressão das comunidades ou da família, como se fossem indivíduos intrusos - os párias da sociedade. 
Tennessee Williams aborda a homossexualidade dentro dessa conjuntura social, política e epistemológica da pedagogia do armário, conforme expressão de Junqueira (2015), usando metáforas e explicitando a sociedade capitalista e as repressões sexuais. Isso explicita a necessidade de se falar sobre o tema como uma denúncia da opressão e da manipulação da sociedade. Há diversas obras em que o autor retratou, também, homens homossexuais. Até 1961, toda a homossexualidade era latente em sua obra, exposta apenas nas entrelinhas, nada era dito, tudo tinha que ser percebido pelas metáforas, pela simbologia e pelos mitos da cultura gay em suas diversas épocas. Depois do grande sucesso de Cat in a Tin Hot Roof (1956), onde a personagem Brick era um homossexual reprimido, casado com Maggie e não podia se assumir, Tennessee trouxe a peça em um ato And Tell Sad Stories of the Death of the Queens [E Contar Tristes Histórias das Mortes das Bonecas, de 1958, mas finalizando apenas em meados da década de 1970] (WILLIAMS, 2001), a primeira de várias outras que abordariam a homossexualidade masculina de forma mais aberta. Personagens lésbicas, no entanto, foram retratadas em apenas nestas duas peças aqui cotejadas. Por este motivo, acredita-se que a extensão destas obras esteja exatamente na maneira em que retratou a homossexualidade, mergulhada na homofobia institucionalizada (LEMOS; IZOTON, 2014), substrato da sociedade de seu tempo.

Why Do You Smoke So Much, Lily? (Por Que Você Fuma Tanto, Lily?, WILLIAMS, 2001, p. 117-128) foi finalizada em fevereiro de 1935. Tem sua última tradução publicada no Brasil em 2001 e encenada em São Paulo entre 2014-15, com direção de Marco Antônio Pâmio, com Ricardo Gelli e Gustavo Haddad no papel de Lily em duas temporadas, respectivamente (DAIMEZI, 2014). No espetáculo Hotel Tennessee do Grupo Tapa, em cartaz em São Paulo em 2018, um trecho da peça também foi encenado, embora a direção não retratou a personagem como homossexual.

Lily é uma personagem imperscrutável, uma intelectual retratada com androginia, mas sem perspectivas pessoais, que está fumando ininterruptamente durante toda a peça. Sua mãe, Sra. Yorke, uma velha da sociedade tradicional sulista, tenta convencê-la a parar de fumar e a se casar para resolver os problemas da filha e os seus próprios, a decadência financeira familiar. Ela não tem as características das Southern Belles. Com esta personagem, Williams tem substrato para trazer à tona as 
mudanças sociais que acometeram a mulher no início do século 20. Lily é indecifrável e sua androgenia denota isso. O dramaturgo a mostra masculinizada, informação percebida na rubrica que descreve a personagem, que supostamente seria uma forma de Tennessee não se colocar em contraponto com o público. Não há, assim, uma exposição objetiva de sua sexualidade na peça.

O documentário The Century of the Self (CURTIS; BBC, 2002) mostra que as mulheres não fumavam publicamente até a década de 1920. A American Tobacco Corporation contratou Edward Bernays (1891-1995), sobrinho de Sigmund Freud (1856-1939), para desenvolver estratégias de marketing para influenciar as mulheres a consumirem cigarros. Um símbolo fálico, o cigarro foi associado psicologicamente com a ideia de desafiar o poder masculino. Assim, as fumantes teriam um pênis próprio e passaram a ser vistas como mulheres imponentes. O cigarro marca sua expressão de independência e não concernente com o status quo, seu instrumento de luta pela igualdade e reconhecimento de direitos na sociedade. Assim, nas mãos de Lily, Williams expõe a sociedade consumista em formação no contexto da Grande Depressão, além de deixar clara a figuração expressionista da homossexualidade. Além disso, o freudismo se consolida como um dos instrumentos mais importantes para fortalecer o consumismo, assim como penetrar com seus protocolos e certificados na cultura, nas artes e no modo estadunidense de ver e entender o mundo (PFISTER; SCHONG, 1997).

O fumar tanto figura o tabagismo quando Sra. Yorke insiste em impor suas opiniões, avessa às pulsões sexuais de Lily. Revela o estresse, mas trazendo à superfície a opressão; a necessidade do alívio das tensões causadas pelas cobranças maternas; busca da satisfação de forma inconscientemente autodestruidora; e ocupação das mãos e boca como foco de concentração, o que fortalece a permanência no armário. Cria para ela uma rota de fuga do patrulhamento familiar. Lily mostra, então, que não aceita as convenções sociais, mas não vê escapatória para seus desejos íntimos na sociedade heteronormativa senão no tabagismo - um vício masculino na década de 1930.

Com relação à sua intelectualidade, também era uma característica até então bastante masculina, pois mulheres raramente frequentavam escolas e universidades, 
liam artigos científicos ou tinham cultura geral abrangente, senão um contato breve com romances e revistas inocentes. Negar a intelectualidade à mulher é uma característica da sociedade burguesa que impõe a subserviência. Mulheres pensantes, autocríticas e que tinham prazer em refletir ou viver de outra forma daquela imposta refletem a postura política sobre o desenvolvimento intelectual, a educação e a ciência no bojo da sociedade. Sua obscuridade revela um caráter eminentemente fascista ao negar o conhecimento acadêmico e científico e dar ouvidos a tradições obsoletas: não só por excluir as mulheres, mas, também, por não querer seres pensantes, pois isso fará emergir posicionamentos contrários aos modelos conservadores, visto perceberem serem escravos/as de um pensamento hegemônico.

Sra. Yorke figura a sociedade sob o vulto heteronormativo do Ato de Comstock e do Código Hays, expondo apenas repressão, impondo a condição tradicional de obediência, delicadeza e conformismo para ser mãe e esposa. A Lei de Comstock criminalizava qualquer tipo de propaganda ou apologia contraceptiva ou ao aborto. Foi instituída por conta da crescente preocupação da sociedade burguesa sobre temas considerados tabus até então como a obscenidade, sexo pré e extramarital, divórcio, homossexualidade, violência sexual, a mudança do papel da mulher na sociedade e o aumento populacional das classes mais baixas. Era uma lei heteronormativa. Por sua vez, em Hollywood havia o Código Hays para os filmes, vigorando entre 1930 a 1968, para censurar beijos, nudez, palavras religiosas, homossexualidade, miscigenação, vícios, gestos e posturas vulgares, entre outros (EPSTEIN; FRIEDMAN, 1995; ABRIL, 2015). A Legião Católica para a Decência (CLOD, sigla em inglês) fortalecia essa prática, exercendo grande influência na indústria cinematográfica, principalmente, no primeiro quarto do século XX, censurando o conteúdo julgado questionável pela Igreja Católica (SADDIK, 1999).

É importante lembrar, também, do Macartismo, que vigorava na década de 1950 e foi caracterizado pela intensa repressão e perseguição política àqueles declarados simpatizantes ou partidários da esquerda política, nomeados de comunistas, baseandose em censura e difamação, tendo-os como traidores, com grande impacto negativo em suas vidas. Todavia, não foi só contra os comunistas, mas também um instrumento de 
repressão e perseguição aos homossexuais, principalmente no serviço público, informa Flores (2015, p. 196).

Williams indica nas rubricas que esta família faz parte da aristocracia sulista falida. Numa época pós-depressão econômica e sem um homem para dirigir os negócios, a mãe de Lily era obrigada a reviver o mito da Southern Belle, impondo à filha a salvação da família. Certamente, ela jamais a encararia como homossexual, por isso sequer toca no assunto. A sociedade queria obscurecer uma mulher como Lily, andrógina e intelectual, com um casamento e colocar o homem como centro da relação para negá-la, capaz de resgatar a mulher do equívoco, apagando para sempre suas inclinações sexuais incoerentes e impedindo que sua inteligência se sobressaísse sobre sua beleza física.

(...) a peça reforça o contraste entre sua própria caracterização [de Lily] e de sua mãe, e obviamente coloca em foco o papel convencionalmente imposto à mulher. Mas, o faz sem que esses aspectos se dissociem da contundente representação crítica de estereótipos da classe média estadunidense tipificados no pensamento e no discurso de Mrs. Yorke: a aceitação incondicional e servil do culto às aparências, o atrelamento preconizado das relações familiares às metas de ascensão social, e o desapreço por toda forma de atividade alheia ou refratária à conquista do sucesso material (BETTI, 2011, p. 113).

Sra. Yorke encena uma sociedade reacionária, que preza as aparências, o materialismo e manipula para mascarar aquilo que não quer ver ou que seja visto. Nega o conhecimento e a reflexão, diminuindo a intelectualidade e sobrepondo a beleza física e os atributos femininos.

A ânsia de Lily por cigarro estampa esta sociedade que se pavoneia expirando fumaça, que se expande e exprime um modo de vida que impõe contradições: explorar sua vitalidade na aparência, com os parcos recursos que ainda sobram da família Sra. York na frente do espelho se embelezando - logo após devolve ao mundo uma visão nublada e obcecada da realidade, impedindo que seja percebida em plenitude, clara na fala de Sra. Yorke: "Lily! A casa está completamente infestada de fumaça e cinzas!” (WILLIAMS, 2012, p. 128). A sociedade oprime; todavia, o oprimido causa desordem e poluição, as cinzas, a neblina. O que Lily produz, portanto, não tem valor, não é desejável. Ela é desqualificada para ser o que se espera dela. O lixo, propriamente dito, é confundido com aquela que o produz. É sobre esta depreciação associativa que Sra. Yorke impõe a humilhação autocrática, alinhando ausência de 
atributos femininos estereotipados com desqualificação, desvantagem e até mesmo baixeza. Sra. Yorke não faz distinção de Lily com a imundície ou a ralé. A expressão de Sra. Yorke traz evidência da rejeição ao homossexual e à mulher que não cumpre seu papel subserviente. Há de sua parte uma imposição social da ideologia heteronormativa e interpretação da realidade cotidiana como patriarcal.

Lily é passiva perante a mãe, que não a deixa responder, nada expressar e, quando sozinha, assombrar-se com sua voz e imagem no espelho, como se a pressão que sente de tudo que a cerca, cobrasse-lhe irremediável e inexoravelmente. Um prenúncio de loucura, como que para calar sua voz, já que a doença mental não seria o que se espera de seres humanos conscientes e que obedecem a padrões. Lily desaparece silenciosa entre fumaça e cinzas. O silêncio em seus muitos sentidos pode se fazer vida ou morte, alegria ou tristeza, mas será infinitamente o lugar do mistério da palavra que, por total falta de tradução, permaneceu ausente, aberta a infinitos sentidos (OLIVEIRA; CAMPISTA, 2007).

A outra peça aqui cotejada, Algo Não Dito (WILLIAMS, 2012, p. 331-358; WILLIAMS, 1983, p. 11-18), foi publicada juntamente com Suddenly, Last Summer [De Repente, no Último Verão] (WILLIAMS, 2014, p. 145-222) em 1958 sob o título Garden District [Bairro dos Jardins]. Deve ter sido escrita provavelmente antes de 1953. Ambas as peças desta publicação tratam de mulheres fortes e dominadoras do centro-sul estadunidense lidando com o tema da homossexualidade. Com relação ao título, Bairro dos Jardins, FALOCCO (2005, p. 1/5) comenta que pesquisadores afirmam que o motivo é o fato de ambas se passarem geograficamente no mesmo lugar, no suntuoso e rico bairro de Nova Orleans - daí o uso da palavra district [bairro]. O autor, todavia, diz que em ambas as peças há uma referência a jardins [garden]. Estes jardins podem ser associados à homossexualidade. Seria a simbologia que o dramaturgo escolheu para tratar da questão, sem tocar no assunto objetivamente, driblando a censura e tornando seu trabalho profundamente expressionista.

O jardim de Cornelia em Algo não Dito é mantido com extremoso cuidado e delicadeza. É privado, impedido de ser visto e mostrado com enfeites em ocasiões específicas. Representa o desejo homossexual no armário, que está seguro quando trancafiado, para não ser perseguido, censurado, confrontado. Possivelmente, o 
jardim se mantém duradouro em sua zona de conforto exatamente por causa do ocultamento. Sebastian Venable em De Repente, no Último Verão, por sua vez, tem um jardim que é uma selva tropical, uma floresta. Selvagem e indisciplinado, configura o desejo homossexual aberto e sem remorsos. Sebastian transgredia normas do comportamento sexual aceitável para a sociedade, o que o levou a um fim trágico.

John Gassner fez os primeiros comentários e crítica sobre estas peças em uma publicação no Brasil em 1965. Nele, o autor coloca Algo Não Dito como uma obra menor e que, as duas peças, poderiam espantar e tornar o público insensível pelos temas não convencionais. A peça longa é alvo de várias páginas de comentários elogiosos, em contraponto com a peça em um ato, que tem apenas um único parágrafo com suas observações: "A primeira peça de Williams, Something Unspoken, não tinha grande importância, apesar de confirmar o conhecimento misterioso que tinha o autor das palpitações do coração feminino" (GASSNER, 1965, p. 290).

Algo Não Dito traz Cornelia, uma mulher de sessenta anos, vivendo um amor secreto de longa data com Grace, mulher de meia idade. É considerada por críticos uma peça marcante sobre o tema lésbico, representando uma quebra de tabu na dramaturgia estadunidense em sua época (QUINLAN, 2012).

Há diversos elementos utilizados por Tennessee Williams para o distanciamento em Algo Não Dito que evitam o envolvimento do público com as personagens e frustram a catarse. O telefone figura o que está fora do pequeno mundo das duas mulheres. Sua campainha traz para dentro da casa das duas mulheres as forças sociais que tentam controlar e patrulhar sua privacidade, lembrando o Ato de Comstock e o Código Hays. Ao tocar, interrompe a relação dialógica entre as duas mulheres, deixando sempre a conversa truncada - algo não dito - e guiando-as para as posições socialmente aceitas: empregada e empregadora. Barra a identificação psicológica com a história ou a moral das personagens. Traz um momento de reflexão, talvez até um riso nervoso ao espectador, um impulso para discernir o que realmente existe no trato social das duas personagens. Quando Cornelia fala ao telefone, Grace se coloca na posição de secretária e se sente desconfortável, inclusive, quando recebe de presente as rosas - símbolo da mulher amada, mas, nesta peça, atuando em um papel confuso, oscilando entre amante e empregada. 
Quando se refere à música, mais uma vez Grace interrompe o diálogo, mencionando o disco que o casal ganhou de Jessie e Gay. Quilan (2012, op. cit., p. 4/7) comenta que o nome Jessie é uma forma pejorativa, homofóbica, de Jesse e Gay, um nome unissex nos EUA, é a forma coloquial de se referir a homossexuais na comunidade homossexual. É possível entender que ambos sejam, também, um casal, tanto de homens ou mulheres, porque nada fica claro. O disco seria, então, um presente de casal para casal. Mesmo se ambos forem interpretados como mulher [Jessie] e homem [Gay], mostrariam uma identidade ambígua, não haveria como fugir da interpretação dos símbolos sobre a homossexualidade, mesmo porque o disco é da cravista e musicóloga polonesa Wanda Landowska (1879-1959), conhecida, também, por ser assumidamente lésbica.

Da mesma forma, a música funciona como um estranhamento do real, uma desalienação ideológica que possibilita refletir, um respiro, trazendo à tona um contexto histórico que desloca o espectador da sua visão supostamente heteronormativa, para um estado de reflexão social sobre questões homossexuais. Grace não tem condições de argumentar com a patroa, já que está em uma situação de oprimida, o que lhe resta é oferecer como contraposição dialética a música. Uma proposta que lembra estéticas alinhadas com o próprio teatro chamado do absurdo ou uma reflexão existencialista.

A indeterminação se amplia neste universo de Williams em que expressar a homossexualidade é um desafio metafórico. Traz o ser e o não ser perante a opressão social, também, em um contexto político definido pelo Macartismo e pelo medo deliberado do comunismo. Por um lado, manifesta o estilo de vida estadunidense, mas revela, acima de tudo, uma diversidade de valores éticos e morais que esta sociedade precisará absorver em relação à homossexualidade. Ao mesmo tempo que transparece a vida retrógrada da sociedade mesquinha, sinalizando o nascimento de um movimento identitário e libertador que só tendia a agigantar-se.

Mergulhadas em uma sociedade anacrônica e silenciadora, as personagens constroem suas vidas sem esperança e sem motivação aparentes. Como se Williams estivesse na eminência de um grito para a reciclagem deste lixo social em que tudo se tornou, impedindo a instabilidade e a conclusão da relação sempre em estado do estar 
para ser. Como que perdidas, estas mulheres estão/são esquecidas em sua própria casa, esperando a sociedade se reciclar.

Algo Não Dito consegue negar a superioridade da relação heterossexual, mesmo com ambiguidades, metáforas e silêncios, por abrir um espaço para o desejo homoerótico feminino: a peça é centrada na relação de Grace e Cornelia. Atribuindo a Cornelia uma posição socialmente poderosa, Williams, em contraste com as solteironas sulistas de algumas peças longas anteriores, mostra a sociedade cruel, colocando em xeque o relacionamento amoroso com a luta de classes.

A homossexualidade é definida pelo silêncio e a sua quebra, pela "frustração antinatural do que se esforça para vir a ser, mas não pode” (OLSEN, 1980, p. 6 apud QUINLAN, 2012, p. 1/7, tradução nossa). ${ }^{4}$ Entre Cornelia e Grace não é percebido um silêncio físico real - como acontece com a personagem Lily. Em vez disso, o que existe é uma comunicação informal e a campainha do telefone silencia o assunto censurado. É na situação silenciosa entre as duas que se evidencia a homoafetividade, ao invés de deixá-la em segundo plano, tal como em De Repente, no Último Verão. É no silêncio que está a insígnia da situação, evidenciada na fala de Cornelia para Grace: "Ça va sans dire, ma petite!" (WILLIAMS, 2012, p. 337). 5 "Todo o silêncio é cheio de informações. As informações no silêncio não são auditivas e, assim, facilmente ignoradas... Mas, se mudarmos a forma de o perceber... Descobrimos que o silêncio é alguma coisa, mas continua sendo nada: o silêncio fala" (GILANI et all, 1985, p. 99-113 apud QUINLAN, 2012, p. 6/7, tradução nossa). ${ }^{6}$

Williams resolve as dificuldades das personagens com este silêncio, como um elemento de distanciamento, evidenciando um caráter épico-lírico na peça - uma fusão de elementos épicos que se assemelham com aqueles que Brecht utilizava, com o lirismo que caracteriza toda a obra do autor desde seus primeiros poemas, passando por contos, novelas e ensaios, até suas peças longas mais famosas.

\footnotetext{
4 Olsen, T. Silences. London: Virago, 1980. "The unnatural thwarting of what struggles to come into being, but cannot".

5 "Não é preciso dizer", tradução conforme nota de rodapé, p. 337.

${ }^{6}$ Gilani, Z. H.; Bucci, W; Freedman, N. The Structure and Language of a Silence. In: Semiotica. 56.1-2 (1985): p. 99-113. "Every silence is full of information. The information in the silence is not auditory and thereby easily ignored. . . But if we shift modalities . . ., we discover that silence is anything but nothing: Silence speaks"
} 
Cornelia fulgura dominante nas situações, superior e independente. Grace, mais passiva, procede como uma propriedade e não como companheira amorosa. É clara a diferença de classes entre elas, portanto. Cornelia faz parte de uma aristocracia falida, decadente, mas que mantém as aparências, inclusive no trato com os empregados. Uma clara associação à Sra. Yorke.

As longas rubricas são líricas, lembrando um conto - outro efeito épico-lírico claramente identificado. Oferecem um respiro para se refletir sobre a relação homoafetiva. Por isso, os elementos de ordem sonora [silêncio, campainha e música] são distanciadores e evitam a identificação com o casal. Dá a oportunidade de operar sobre a obra, codificando os símbolos, mas sem envolvimento.

O valor destas peças é inegável por trazer os anos da Depressão Econômica, do American way of life, da história da mulher, da censura e da homossexualidade na sociedade estadunidense. O autor utiliza simbologias, metáforas, distanciamento e alienação que lembram elementos brechtianos para tais representações, desafiando a forma dramática convencional. Os expedientes do épico que surgiriam na dramaturgia estadunidense foram utilizados a partir do final da década de 1950 e, principalmente, na década seguinte. Tennessee Williams diverge da forma que Brecht os utilizou, todavia. Pode-se afirmar que seus recursos eram épico-líricos e expressionistas. Ao empregá-los, o autor cria um estilo próprio, associando o épico ao lirismo, trazendo o distanciamento do espectador, sem lançar mão da veia poética que acabou por se tornar sua marca registrada (TOLEDO; SILVA, 2018).

Nestas peças em um ato de Tennessee, as personagens não apontam qualquer modificação, em consonância com essas inovações de formas dramatúrgicas estadunidenses para a época. Elas continuam as mesmas do início ao fim, sem transformação. Não há um momento de purificação da alma, de clímax, de catarse. Entende-se, portanto, que estas peças não têm objetivos psicanalíticos, mas uma reflexão crítica devido à não identificação absoluta com as personagens.

Lidando com matérias que fatalmente poderiam levar à catarse, as duas peças poderiam ser levadas a soluções dramatúrgicas aristotélicas. As personagens poderiam passar por escolhas mal realizadas, da felicidade para a infelicidade, provocando na plateia sentimentos de terror e piedade, depurando as emoções humanas. Mas, não há 
elementos que identifiquem heróis ou descarga de emoções, um conflito aparente ou seu clímax.

Williams faz o alinhamento de questões sociais com inovações dramatúrgicas. $\mathrm{O}$ tempo histórico e seus efeitos sobre as duas famílias abordadas submergem uma dramaturgia atenta às mulheres de diferentes idades de duas camadas sociais diferentes. As personagens lidam com seus problemas sem redenção, o que remete à situação típica da peça em um ato e ao épico-lírico, na qual não há mudança possível, mas apenas à certificação de nada mudar.

O uso de símbolos e alegorias revela o Expressionismo como recurso concreto para manifestar sua crítica à sociedade. O mesmo acontece com as características épico-líricas. Os diálogos expressam modos de pensar marcadamente alinhavados por questões sócio-históricas. O indivíduo não pode decidir ou fazer, está sujeito ao que a vida proporcionar. Isto fica evidente nas discrepâncias dialógicas entre Lily e sua mãe, Grace e Cornelia.

A depressão de Lily não pode ser interpretada como uma situação de loucura, afetação ou desequilíbrio emocional, como canonicamente as principais personagens femininas de Tennessee são encaradas. É apenas a forma como ela reage à situação que enfrenta. Com Grace isso também é observado quando procura fugir da conversa explícita com Cornelia.

As duas peças são paradigmas da dramaturgia inovadora de Tennessee Williams. Fica claro que, para o dramaturgo, o que leva o teatro a uma maior aproximação com o real é a aparência de realidade e não a sua imitação.

$$
* * *
$$

\section{REFERÊNCIAS}

ABRIL. É Verdade que Existia Censura em Hollywood? In: Mundo Estranho. Disponível em: <http://mundoestranho.abril.com.br/materia/e-verdade-que-existiacensura-em-hollywood>.Acesso: 31 Jul 2015.

ARNAUT, L. M. Tennessee Williams: Algo Não Dito. São Paulo: Giostri, 2017. 116 p. 
BETTI, M. S. Alegoria Política e Representação em Camino Real, de Tennessee Williams. In: CHAIA, Miguel (org). Arte e Política. São Paulo, Programa de Estudos Pós-graduados em Ciências, 2007.

BETTI, M. S. Apresentação. In: WILLIAMS, Tennessee. Mister Paradise e Outras Peças em Um Ato. São Paulo: É Realizações, 2011, p. 7-32.

BETTI, M. S. Mr. Paradise and Other Plays, de Tennessee Williams: Apontamentos para uma Análise Formal. In: Literatura e Sociedade, No 15, São Paulo: 2011, p. 94-121. In: <www.revistas.usp.br/ls/article/download/64548/67193>. Acesso em 20 jul 2015 .

BLACKWELL, L. Tennessee Williams and the Predicament of Women. In: South Athantic Bulletin. Atlanta, Vol. 35, No 2, Mar, 1970. p. 9-14. Disponível em: <http://www.jstor.org/stable/ 3197002>. Acesso: 28 Fev. 2018.

CURTIS, A.; BBC. The Century of the Self. (documentário) Londres, 2002. Disponível em: <https://vimeo.com/65256698> Acesso: 20 Jul. 2015.

DAIMEZI, M. Marco Antônio Pâmio Mistura Peças de Tennessee Williams para Falar de Personagens Marginais. In: Cultura FM, 12/11/2014. Disponível em: <http://culturafm.cmais.com.br/radiometropolis>. Acesso: 7 Jul. 2015.

EPSTEIN, R.; FRIEDMAN, J. The Celluloid Closet. (documentário) 1995. Disponível em: <http://playmovie.nimaturrizkiyah.com/?movie=0112651>. Acesso: 31 Jul. 2015.

FALOCCO, J. Gardens of Desire: Towards a Unified Vision of Garden District. In: The

Tennessee Williams Annual Review, No 7, 2005. Disponível em:

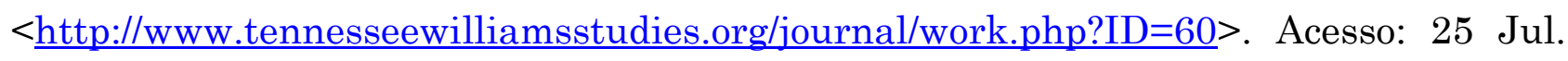
2015.

FLORES, F. T. Da Depressão às Raízes do Macartismo: Representação de Questões Sócio-históricas em American Blues, de Tennesse Williams. São Paulo: Humanitas, 2015. 317 p.

FOLEY, R. Women as Victims in Tennessee Williams' First Three Major Plays. Dissertação (Mestrado na Faculty of the College of Arts and Sciences). 2013. 278p. Disponível em: <http://digitalcommons.liberty.edu>. Acesso: 1 Abr. 2017. GASSNER, J. Rumos do Teatro Moderno. Rio de Janeiro: Lidador, 1965. 
JUNQUEIRA, R. D. Pedagogia do Armário. In: Cult - Revista Brasileira de Cultura. No 202, Ano 18. São Paulo: Bregantini. Junho, 2015. p. 38-41.

KATARIA, G. R. The Hetarias (Maggie, Myrtle, Blanche). In: BLOOM, H. (ed). Bloom's Modern Critical Interpretations: Tennessee Williams' Cat in Hot Tin Roof - New Edition. Nova Iorque: Infobase Publishing, 2011. p. 13-49.

KEITH, T. Introduction: a Mytic Imagination. In: WILLIAMS, T. Now the Cats with Jellewed Claws and Other One-act Plays. Thomas Keith (ed.). Nova Iorque: New Directions, 2016. p. xi-xv.

LEMOS, A. F.; IZOTON, A. C. Tennessee Williams e o Teatro Marginal Gay. In: Linguagem - Estudos e Pesquisas. Vol. 18, No 1, Catalão, GO, jan/jun, 2014. p. 4964.

MATHUR, C. Women in the Plays of Eugene $\mathrm{O}^{\prime}$ Neill and Tennessee Williams. Jaipur: Rawat Publications, 2002. 198 p.

OLIVEIRA, V. M. R.; CAMPISTA, V. R. O Silêncio: Multiplicidade de Sentidos. In: SINAIS - Revista Eletrônica - Ciências Sociais. Vitória: CCHN, UFES, Edição n.02, v.1, Outubro. 2007. pp.107-120. Disponível em: <http://www.periodicos.ufes.br/sinais/article/viewFile/2850/2316>. Acesso: 06 Ago. 2015.

PFISTER, J; SCHNOG, N. Inventing the Psychological - Towards a Cultural History of Emotional Life in America. Yale: Yale University Press, 1997.

QUINLAN, S. Something Unspoken: Dramatizing the Lesbian Closet. In: The Tennessee William's Annual Review. No 13, 2012. Disponível em: <http://www.tennesseewilliamsstudies.org/journal/work.php?ID=117>. Acesso: 26 Jun. 2015.

SADDIK, A. J. Tennessee Williams and the of Excess: the Strange, the Crazed, the Queer. Cambridge: Cambridge University Press, 2015. 180p

SADDIK, A. J. The Politics of Reputation - The Critical Reception of Tennessee Williams' Later Plays. Cranbury: Associated University Presses, 1999. 173 p.

SILVA, L. Memória Histórica na Dramaturgia de Tennessee Williams. In: Fênix, Uberlândia, v. 2, No 3, 2005. p. 1-12. 
STRNADOVÁ, A. Tennessee Williams's Southern Belles. Tese de Bacharelado (Língua Inglesa e Literatura) Faculdade de Artes da Masaryk University, 2013.

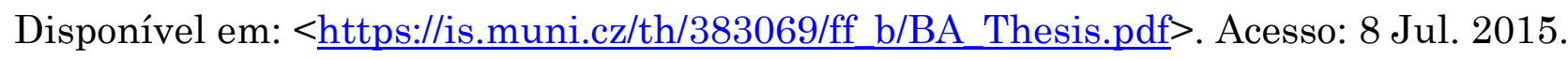
TOLEDO, L. M. A.; SILVA, D. G. Not About Nightingales: o Épico-lírico de Tennessee Williams. In: Revista Cena, Porto Alegre, n. 26, p. 6-19, set./dez. 2018. Disponível em: <http://seer.ufrgs.br/cena >. Acesso: 9 Nov. 2018.

TORRES, B. Tennessee Williams em Um Ato. In: Opinião \& Notícia, 21 jan 2012. Disponível em: <http://opiniaoenoticia.com.br/opiniao/tennessee-williams-em-umato/>. Acesso: 7 Jul. 2015.

TRIPLETT, J. L. Tennessee Williams's Treatment of Women in His Major Plays. Dissertação (Mestrado pela Faculty of Atlanta University). Atlanta University, Atlanta, 1988. Disponível em: <http://digitalcommons.auctr.edu $>$. Acesso: 26 Jun. 2015.

WILliams, T. 27 Carros de Algodão e Outras Peças em Um Ato. Grupo Tapa (trad.). São Paulo: É Realizações, 2012.

WILliams, T. Algo que Não é Falado. (trad. Sérgio B. Café) In: Cadernos de Teatro, Rio de Janeiro: O Tablado. No 99, out/nov/dez 1983. p. 11-18. Disponível em: $<\underline{\text { http://otablado.com.br/wpcontent/uploads/notebookstheater/a0178c55c41d122bfa3c86 }}$ a106cbad88.PDF>. Acesso: 15 Jul. 2015.

WILliAMS, T. Mister Paradise e Outras Peças em Um Ato. Grupo Tapa (trad.). São Paulo: É Realizações, 2001.

WILLIAMS, T. O Zoológico de Vidro/De Repente, no Último Verão/Doce Pássaro da Juventude. Grupo Tapa (trad.). São Paulo: É Realizações, 2014.

Recebido em agosto de 2018. Aprovado em outubro de 2018. Publicado em dezembro de 2018. 